\title{
Validity of the Egyptian version of Sino- Nasal Outcome Test-22 and its predictive value in evaluation of patients undergoing septoplasty surgery
}

\author{
M. H. Abdelazim* (iD and M. E. Alsobky
}

\begin{abstract}
Background: The purpose of this study is to evaluate the patients undergoing septoplasty surgery via the Egyptian version of Sino-Nasal Outcome Test-22 (SNOT-22). Sixty patients were selected from 77 deviated nasal septum patients who had undergone septoplasty surgery represent the group 1, and another 60 healthy subjects were selected to be the control group 2. All patients as well as the control group were exposed to SNOT-22 questionnaire preoperatively and 3 months postoperatively.

Results: SNOT-22 questionnaire was found to be improved from a mean \pm SD of $29.0 \pm 10.7$ preoperatively to 13.2 \pm 3.22 postoperatively; the control group has a mean of $13.8 \pm 2.64$.

Conclusion: The Egyptian version of SNOT-22 is an effective tool in evaluating the operation results in patients with deviated nasal septum after septoplasty surgery.
\end{abstract}

Keywords: Septoplasty, Sinonasal, Deviated septum

\section{Background}

Septal deviation is one of the most common causes of nasal obstruction and is a prevalent problem among the general population [1]. As such, septoplasty is among the most frequently performed procedures in otolaryngology and facial plastic surgery [2].

Outcomes of surgical procedures were evaluated using different objective measures as well as subjective quality of life questionnaires. The 22-item Sino-Nasal Outcome Test (SNOT-22) is a widely applied patient-reported outcome instrument used to assess the severity of symptoms associated with chronic rhinosinusitis [3]. It is a validated questionnaire of disease-specific, quality-of-life (QoL)-related measures of sinonasal function [4].

\footnotetext{
* Correspondence: mohammedabdelazeem35@yahoo.com Otorhinolaryngology Department Al-Azhar Faculty of Medicine, New Damietta, New Damietta 34518, Egypt
}

(c) The Author(s). 2020 Open Access This article is licensed under a Creative Commons Attribution 4.0 International License, which permits use, sharing, adaptation, distribution and reproduction in any medium or format, as long as you give appropriate credit to the original author(s) and the source, provide a link to the Creative Commons licence, and indicate if changes were made. The images or other third party material in this article are included in the article's Creative Commons licence, unless indicated otherwise in a credit line to the material. If material is not included in the article's Creative Commons licence and your intended use is not permitted by statutory regulation or exceeds the permitted use, you will need to obtain permission directly from the copyright holder. To view a copy of this licence, visit http://creativecommons.org/licenses/by/4.0/. 
informed consent was given by the patients for their clinical records to be used in this study.

There were no restrictions or directions for the surgeon regarding the surgical procedure and use of postoperative nasal pack or nasal splints.

Inclusion criteria were deviated nasal septum with nasal breathing problems not responding to medical treatment. Exclusion criteria were the following:

- Septoplasty in combination with sinus and other surgeries

- Rhinoplasty operation

- Age less than 18 years and more than 55 years

- Patients who did not complete the study and follow-up.

- Patients who did not perform our medical consent.

The diagnosis was based on endoscopic examination of the nose combined with patients' symptoms.

\section{Materials}

Preoperatively, a SNOT-22 questionnaire was completed at the outpatient clinic.

Postoperatively, another SNOT-22 questionnaire was completed at the follow-up visit to the outpatient clinic 3 months after surgery.

\section{Technique}

Translation and cultural adaptation of the SNOT-22 was used in the following steps:

Step 1: All the items of the English version of the SNOT-22 (Table 1) were forward-translated by two translators separately into the Egyptian dialect. The translators avoided word-for-word translations and used simple terms that could be easily understood by the subjects. The final draft was created and finally reviewed by an ENT specialist for medical viewpoint.

Step 2: The draft obtained was back-translated into English by two translators different from those who translated the first forward translation.

Step 3: The English draft obtained was reviewed and compared with the original version. It was confirmed that similar expressions had been used.

Scoring of SNOT-22 Egyptian version was done for each participate preoperatively and 3 months postoperatively.

The scoring of SNOT-22 points was interpreted as $0=$ no problem, 1 = very mild problem, $2=$ mild or slight problem, $3=$ moderate problem, $4=$ severe problem, 5 = problem as bad as it can be) [6].

Table 1 English form of SNOT-22

\begin{tabular}{|c|c|c|c|c|c|c|c|}
\hline$N$ & Item & No problem (0) & $\begin{array}{l}\text { Very mild } \\
\text { problem (1) }\end{array}$ & $\begin{array}{l}\text { Mild/slight } \\
\text { problem (2) }\end{array}$ & $\begin{array}{l}\text { Moderate } \\
\text { problem (3) }\end{array}$ & $\begin{array}{l}\text { Severe } \\
\text { problem (4) }\end{array}$ & $\begin{array}{l}\text { Problem as bad } \\
\text { as it can be (5) }\end{array}$ \\
\hline 1 & Need to blow nose & & & & & & \\
\hline 2 & Sneezing & & & & & & \\
\hline 3 & Runny nose & & & & & & \\
\hline 4 & Nasal obstruction/mouth breathing & & & & & & \\
\hline 5 & Loss of smell/taste & & & & & & \\
\hline 6 & Cough & & & & & & \\
\hline 7 & Postnasal discharge & & & & & & \\
\hline 8 & Thick nasal discharge & & & & & & \\
\hline 9 & Ear fullness & & & & & & \\
\hline 10 & Dizziness & & & & & & \\
\hline 11 & Ear pain & & & & & & \\
\hline 12 & Facial pain/headache & & & & & & \\
\hline 13 & Difficulty falling asleep & & & & & & \\
\hline 14 & Wake up at night & & & & & & \\
\hline 15 & Lack of a good night sleep & & & & & & \\
\hline 16 & Wake up tired & & & & & & \\
\hline 17 & Fatigue & & & & & & \\
\hline 18 & Reduced productivity & & & & & & \\
\hline 19 & Reduced concentration & & & & & & \\
\hline 20 & Frustrated/rest less/irritable & & & & & & \\
\hline 21 & Sad & & & & & & \\
\hline 22 & Embarrassed & & & & & & \\
\hline
\end{tabular}


Table 2 Demographic data of our patients

\begin{tabular}{|c|c|c|c|c|c|c|c|c|}
\hline \multirow[b]{2}{*}{ Gender: } & \multicolumn{2}{|c|}{$\begin{array}{l}\text { Group } 1 \\
(n=60)\end{array}$} & \multicolumn{2}{|c|}{$\begin{array}{l}\text { Group 2 } \\
(n=60\end{array}$} & \multicolumn{2}{|c|}{$\begin{array}{l}\text { Total } \\
(n=120)\end{array}$} & \multicolumn{2}{|c|}{ Test of significance } \\
\hline & No. & $\%$ & No. & $\%$ & No. & $\%$ & $x^{2}$ & $p$ value \\
\hline Males & 35 & 58.33 & 33 & 55.0 & 68 & 56.67 & 0.0656 & 0.1871 \\
\hline Females & 25 & 41.67 & 27 & 45.0 & 52 & 43.33 & 0.0713 & 0.1956 \\
\hline Total & 60 & 100 & 60 & 100 & 137 & 100 & & \\
\hline$p$ value & \multicolumn{2}{|c|}{$>0.05$} & \multicolumn{2}{|c|}{$>0.05$} & \multicolumn{2}{|c|}{$>0.05$} & & \\
\hline Age (years) & & & & & & & $t$ test & $p$ value \\
\hline - Range & \multicolumn{2}{|c|}{$18-55$} & \multicolumn{2}{|c|}{$19-52$} & \multicolumn{2}{|c|}{$18-55$} & 0.03443 & 0.3078 \\
\hline - Mean \pm SD & \multicolumn{2}{|c|}{$36.6 \pm 7.21$} & \multicolumn{2}{|c|}{$38.2 \pm 6.94$} & \multicolumn{2}{|c|}{$37.5 \pm 7.03$} & & \\
\hline
\end{tabular}

\section{Assessment \\ Reliability}

Reliability is defined as the extent to which the SNOT22 produces the same results on repeated trials. It is the stability of scores over time assessed through a testretest reproducibility by measuring correlations between the SNOT-22 at time 1 and at time 2 (1 week after) for the same patients with septal deviation. Internal consistency or homogeneity concerns the extent to which items on the test are measuring the same thing.

\section{Validity}

Validity is defined as the extent to which the SNOT-22 measures what it purports to measure. Content validity was assessed in the development of the original form and maintained by the process of forward and backward translation. Criterion validity compares test score performance to a gold standard, which in the case of the QOL scales does not exist.

Construct validity is the degree to which the SNOT-22 measures the theoretical construct that it is intended to measure and includes convergent and discriminant or divergent validity. Convergent validity was assessed by comparing the two scores: SNOT-22 and RSDI. A convergent validity was assessed because we desired to see how closely the SNOT-22 was related to another questionnaire (RSDI) of the same construct. Discriminant validity, which is the ability to discriminate between known groups, was determined by comparing two groups: patients with septal deviation and healthy volunteers.

\section{Responsiveness or sensibility}

The scores before (at time 1) and 3 months after septoplasty were compared to detect if they were significant clinical change after surgical intervention.

Analyses of the data were performed using Windows, version 23. Data are expressed as the mean values (with standard deviations [SDs]), and all statistical tests are 2tailed. Non-parametric tests were applied to the data. Chi-square tests $(\chi 2)$, paired $t$ test, and Student's $t$ test were used to identify differences between groups (according to ANOVA test of variance).

Then, probability was tested to determine the validity of the test as follows: values of $p>0.05$ were considered insignificant, while $p<0.05$ were considered to indicate statistical significance.

The interpretation of correlation coefficient $(r)$ was plotted and calculated according to Hopkins et al. [7] excellent correlation $(>0.91)$, good correlation $(0.71-0.90)$, moderate correlation (0.51-0.70), acceptable correlation $(0.31-0.50)$, and low correlation $(<0.30)$.

\section{Results}

The study included 77 patients undergoing septoplasty, of which only 60 patients completed the study and represented group 1, and 60 healthy volunteers were selected to be the control group 2. The average age of the patients was 30.5 years (range, 18-55 years) which represented in Table 2).

Demographic characteristics of the studied patients of our groups are demonstrated in Table 2. The total SNOT22 score of the studied groups is represented in Table 3.

Table 3 Sino-Nasal Outcome Test-22 score of the studied groups

\begin{tabular}{llll}
\hline SNOT-22 points & Group 1 Septoplastic surgery group & & Group 2 \\
\cline { 2 - 3 } & Preoperative & 3 months postoperative & Controls \\
\hline Range & $18-38$ & $9-24$ & $9-18$ \\
Mean \pm SD & $29.0 \pm 10.7$ & $13.2 \pm 3.22$ & $13.8 \pm 2.64$ \\
$t$ test & 0.6345 & & $0.7327^{\mathrm{a}}$ \\
$p$ value & 0.0024 & & $0.0001^{\mathrm{a}}$ \\
Improvement change & $15.8 \pm 7.48(54.4 \%)$ & & \\
\hline
\end{tabular}

${ }^{a}$ Comparison between preoperative patients and controls 
Table 4 Statistical analysis of SNOT-22 score pre- and postoperative

\begin{tabular}{|c|c|c|c|c|c|c|}
\hline & \multicolumn{2}{|c|}{$\begin{array}{l}\text { Preoperative } \\
(n=60)\end{array}$} & \multicolumn{2}{|c|}{$\begin{array}{l}\text { Postoperative } \\
(n=60)\end{array}$} & \multicolumn{2}{|c|}{ Test of significance } \\
\hline & Mean & $\pm \mathrm{SD}$ & Mean & $\pm \mathrm{SD}$ & $t$ test & $p$ \\
\hline Nasal obstruction score & 3.5 & 1.1 & 1.2 & 0.82 & 5.121 & 0.015 \\
\hline Nasal symptoms score & 16.2 & 2.3 & 6.3 & 1.6 & 7.544 & 0.001 \\
\hline Non-nasal symptoms score & 3.7 & 1.5 & 1.7 & 1.3 & 4.514 & 0.018 \\
\hline General health score (QoL) & 9.1 & 3.2 & 5.2 & 1.6 & 2.921 & 0.035 \\
\hline Total SNOT\# score & 29.0 & & 13.2 & & 4.872 & 0.019 \\
\hline
\end{tabular}

QoL quality of life

Analysis of the SNOT-22 score pre- and postoperative is represented in Table 4 .

The distribution of cases according to their nasal obstruction symptom and the operation results on such symptom is represented in Tables 5 and 6 .

The distribution of cases according to their nasal symptoms improvement is showed in Table 7.

The distribution of cases according to their non-nasal symptoms and the operation results for such symptoms is demonstrated in Tables 8 and 9 .

The improvement in general health and quality of life is represented in Table 10.

\section{Discussion}

The SNOT score was originally developed as a rhinosinusitis-specific, health-related questionnaire and combines both symptoms related to the nose and general health. It has been validated in this respect. The use of the SNOT score Egyptian version as a measure of outcome after septal surgery is novel. This is a single questionnaire that can quickly be completed in an out-patient setting by the patient and can be used on a regular basis. In what is effectively a quality-of-life operation, the figures generated are useful when assessing outcome [8].

Seventy-seven patients underwent surgery in this study, but only 60 of them came for the postoperative control, and all patients were at the out patient's clinic when they reported their symptoms which should minimize errors in their reporting.

This study assumes that nasal septoplasty leads to a better nasal Qol and a significant improvement for all symptoms.

To our knowledge, this is the first study that uses Sino-Nasal Outcome Test-22 in a special Egyptian version to evaluate patients' symptoms and QoL after nasal septoplasty surgery.

Table 5 Distribution of cases according their nasal obstruction

\begin{tabular}{lll}
\hline Item & Number & $\%$ \\
\hline Patient with nasal obstruction & 60.0 & 100.0 \\
\hline
\end{tabular}

We see that more men than women undergo nasal septum surgery. The reason for this is not clear, but Bugten et al. [9] think that men tend to be involved in activities that are associated with a higher risk for nasal traumas. Nevertheless, both men and women respond to nasal septum surgery and reach the same Qol and symptom level postoperatively.

The patients report a mean preoperative SNOT-22 of $29.0 \pm 10.7$. Comparing the preoperative results from the SNOT-22 questionnaire with results after 3 months postoperatively, we see that the patients with septal deviations report SNOT-22 QoL at a mean \pm SD of $13.2 \pm 3.22$.

Same results reported previously by other questionnaire comparing other septoplasty QoL studies [10-12].

Nasal septal surgery leads to a highly significant improvement in mean SNOT-22 score $15.8 \pm 7.48$ (54.4\%). For all subsets in the questionnaire, we find a highly significant improvement. When comparing the postoperative results with healthy controls $(p<0.001)$, we find that the patients reach nearly the same level as the controls in the subset of the questionnaire where the symptom burden is comparable in the groups.

Our SNOT-22 results are well in accordance with the expected results of Septoplasty, which decreased from 29.0 to 13.2 with a mean QoL change of 15.8 points (54.4\%). However, Hyzctonen et al. [10] found a mean difference of SNOT-22 score, 21.5 points.

Regarding nasal symptoms, the patients had a high level of significance than the healthy controls $(p<0.05$ to $<0.001)$. For symptoms such as nasal obstruction, change in sense of smell, nasal secretions, need to blow the nose, we found a greater reduction in symptoms in the patient group postoperatively.

Table 6 The operation results of patient with nasal obstruction

\begin{tabular}{lll}
\hline Results of operation & $\begin{array}{l}\text { Number } \\
\mathbf{N = 6 0}\end{array}$ & $\%$ \\
\hline Improved & 50 & 83.3 \\
Not improved & 4 & 16.67 \\
Worsening & 0 & 0.00 \\
Total & 60 & 100 \\
\hline
\end{tabular}


Table 7 The operation results of patient with nasal symptoms

\begin{tabular}{lll}
\hline Results of operation & $\begin{array}{l}\text { Number } \\
\mathbf{N = 6 0}\end{array}$ & $\%$ \\
\hline Improved & 48 & 80 \\
Not improved & 12 & 20 \\
Worsening & 0 & 0.00 \\
Total & 60 & 100 \\
\hline
\end{tabular}

In the previous studies of septoplasty, chronic rhinosinusitis, and nasal polyposis, the decrease in symptom score was $17.0,12.6$, and 17.7 , respectively $[5,13]$.

Hytonen et al. [10] reported after 6 months of septoplasty surgery, as measured by the SNOT-22, the need to blow the nose, sneezing, runny nose, nasal obstruction, loss of smell or taste, postnasal discharge, facial pain/pressure, difficulty in falling asleep, and waking up at night improved significantly.

SNOT-22 in this study showed that septoplasty resulted in significant improvement in nasal obstruction $83.3 \%$. A previous report found up to $75 \%$ improvement in nasal obstruction by Buckland et al. [5] compares favorably with other studies ranged from 70 to $80 \%[14,15]$.

An overall improvement in the mean SNOT-22 score of $47 \%$ could be defined as an improvement [5]. A high patient satisfaction and decreased medication use. Severe preoperative nasal obstruction indicated a higher predicted improvement [12].

This study confirms the hypothesis that septoplasty for the treatment of adults with nasal septum deviation results in improvements in the disease-specific QoL measures using SNOT-22 questionnaire 3 months after the surgery.

Previous studies showed the same results with other NOSE tests questionnaire. Bezerra et al. [16] found a statistically significant improvement in their NOSE questionnaire scores 3 months after surgery (median $(\mathrm{md})=75$, interquartile interval $(\mathrm{IIQ})=26$ vs. $\mathrm{md}=10$, IIQ $=20)(p<0.001)$ and a strong statistically significant correlation between the improvement in postoperative score and the preoperative score in the NOSE questionnaire $(r=-0.789, p<0.001)$. The effect's magnitude was significant and three times higher than the standard deviation, indicating an important treatment effect. They did not find differences between the genders in their sample of patients; despite the fact that quality of life studies published about other diseases showed a worsening in the quality of life among females [17].

Table 8 Distribution of cases according to their non-nasal symptoms

\begin{tabular}{lll}
\hline Item & $\begin{array}{l}\text { Number } \\
\boldsymbol{N}=\mathbf{6 0}\end{array}$ & $\%$ \\
\hline Patient with non-nasal symptoms & 48 & 80.0 \\
\hline
\end{tabular}

Table 9 The operation results of patient with non-nasal symptoms

\begin{tabular}{lll}
\hline Results of operation & $\begin{array}{l}\text { Number } \\
\mathbf{N = 4 8}\end{array}$ & $\%$ \\
\hline Improved & 26 & 54.16 \\
Not improved & 22 & 45.84 \\
Worsening & 0 & 0.00 \\
\hline
\end{tabular}

This study had some limitations as we did not compare the SNOT-22 with other QoL tests regarding nasal septum surgery such as SNOT-20 [8], generic 15D questionnaires [10], Nottingham Health Profile (NHP), General Health Questionnaire (GHQ) [15], etc.

Also, we did not compare different age groups as some studies [10] reported a poor test with old age group.

The short follow-up period (3 months) may affect the SNOT-22 questionnaire, as this is the least period in the studied literatures which ranged from 6 to 12 months.

We did not classify nasal symptoms according to their severity as other study reported that the more nasal symptoms the patients had pre- or postoperatively, the poorer the QoL [10].

Also we did not compare patients who receive treatment and not receiving treatment as Hytonen et al. [10] suggested treatment combination with septoplasty in septal deviation patients. There are also signs that nasal mucosal edema causes blockage and other nasal symptoms and medical treatment has not eased the symptoms. It can be recommended because it is well tolerated [14].

\section{Conclusion}

In this study, we have shown that nasal septoplasty leads to a better sino-nasal Qol and a highly significant symptom improvement.

The Egyptian version of SNOT-22 is an effective tool in evaluating nasal septum patients QoL after septoplasty surgery.

The results of this study also encourage the use of a systematic questionnaire, e.g., the SNOT-22, for patients with nasal symptoms in daily clinical practice to estimate the severity of symptoms and successful surgery.

Table 10 The operation results of patient with general health score (quality of life) symptoms

\begin{tabular}{lll}
\hline Results of operation & $\begin{array}{l}\text { Number } \\
\mathbf{N = 6 0}\end{array}$ & $\%$ \\
\hline Improved & 37 & 61.67 \\
Not improved & 23 & 38.33 \\
Worsening & 0 & 0.00 \\
Total & 60 & 100 \\
\hline
\end{tabular}




\section{Abbreviations}

SNOT-22: The 22-item Sino-Nasal Outcome Test; QoL: Quality-of-life; Md: Median; IIQ: Interquartile interval

\section{Acknowledgements}

Not applicable.

\section{Authors' contributions}

Abdelazim MH and Alsobky ME contributed to the study design, carried out the collection and assembly of data, drafted the manuscript, did the feature extraction statistical work, and reviewed the manuscript. Abdelazim $\mathrm{MH}$ and Alsobky ME read and approved the final manuscript.

\section{Funding}

No funding.

\section{Availability of data and materials}

The datasets used and or analyzed during the current study are available from the corresponding author on reasonable request.

\section{Ethics approval and consent to participate}

The study is approved by the Committee for Medical Research Ethics in Al-Azhar University, Egypt. A written informed consent was given by the patients for their clinical records to be used in this study.

\section{Consent for publication}

Not applicable.

\section{Competing interests}

The authors declare that they have no competing interests.

Received: 16 March 2020 Accepted: 27 November 2020

Published online: 14 December 2020

\section{References}

1. Fettman N, Sanford T, Sindwani R (2009) Surgical management of the deviated septum: techniques in septoplasty. Otolaryngol Clin North Am 42(2):241-252 viii

2. Most SP, Rudy SF (2017) Septoplasty Basic and advanced techniques. Facial Plast Surg Clin North Am 25(2):161-169. https://doi.org/10.1016/j.fsc.2016.12. 002 Epub 2017 Feb 21

3. Kordjian HH, Schousboe LP (2017) Sixty-three patient-based survey-Can Sino-Nasal Outcome Test-22 be a suitable evaluation method for septoplasty and turbinectomy? Clin Otolaryngol. 42(6):1373-1377. https:// doi.org/10.1111/coa.12881 Epub 2017 Apr 20

4. Lange B, Thilsing T, Al-kalemji A, Baelum J, Martinussen T, Kjeldsen A (2011) The Sino-Nasal Outcome Test 22 validated for Danish patients. Dan Med Bull. 58(2):A4235

5. Buckland JR, Thomas S, Harries PG (2003) Can the Sino-Nasal Outcome Test (SNOT-22) be used as a reliable outcome measure for successful septal surgery? Clin Otolaryngol Allied Sci. 28(1):43-47

6. Satish HS, Sreedhar KT (2013) Septoplasty outcome using Snot-22 Questionnaire Study. IOSR J Dental Med Sci (IOSR-JDMS). 6(5):34-38

7. Hopkins C, Gillett S, Slack R (2009) Psychometric validity of the 22-item Sinonasal Outcome Test. Clin Otolaryngol. 34(5):447-454

8. Baumann I (2010) Quality of life before and after septoplasty and rhinoplasty. GMS Curr Top Otorhinolaryngol Head Neck Surg 9:Doc 06

9. Bugten $\mathrm{V}$, Nilsen $\mathrm{AH}$, Thorstensen WM, Moxness MH, Amundsen MF, Nordgård S (2016) Quality of life and symptoms before and after nasal septoplasty compared with healthy individuals. BMC Ear Nose Throat Disord 28(16):13

10. Hytonen M, Blomgren K, Lilja M, Makitie AA (2006) How we do it: septoplasties under local anaesthetic are suitable for short stay surgery; the clinical outcomes. Clin Otolaryngol. 31(1):64-68

11. Arunachalam PS, Kitcher E, Gray J (2001) Nasal septal surgery: evaluation of symptomatic and general health outcomes. Clin Otolaryngol Allied Sci. 26(5):367-370

12. Stewart MG, Smith TL, Weaver EM (2004) Outcomes after nasal septoplasty: results from the nasal obstruction septoplasty effectiveness (NOSE) study. Otolaryngol Head Neck Surg. 130(3):283-290
13. Gillett S, Hopkins C, Slack R (2009) A pilot study of the SNOT 22 score in adults with no sinonasal disease. Clin Otolaryngol. 34(5):467-469

14. Hytönen ML, Bäck LJJ, Malmivaara AV (2009) Radiofrequency thermal ablation for patients with nasal symptoms: a systematic review of eVectiveness and complications. Eur Arch Otorhinolaryngol. 266(8): $1257-1266$

15. Arunchalam PS, Kitcher E, Gray J, Wilson JA (2001) Nasal septum surgery: evaluation of symptomatic and general health outcomes. Clin Otolaryngol 26:367-370

16. Bezerra TF, Stewart MG, Fornazieri MA, Pilan RR, Pinna Fde R, Padua FG, Voegels RL (2012) Quality of life assessment septoplasty in patients with nasal obstruction. Braz J Otorhinolaryngol. 78(3):57-62

17. Arrington-Sanders R, Yi MS, Tsevat J, Wilmott RW, Mrus JM, Britto MT (2006) Gender differences in health-related quality of life of adolescents with cystic fibrosis. Health Qual Life Outcomes 4:5

\section{Publisher's Note}

Springer Nature remains neutral with regard to jurisdictional claims in published maps and institutional affiliations.

\section{Submit your manuscript to a SpringerOpen ${ }^{\circ}$ journal and benefit from:}

- Convenient online submission

- Rigorous peer review

- Open access: articles freely available online

- High visibility within the field

- Retaining the copyright to your article

Submit your next manuscript at $\boldsymbol{\nabla}$ springeropen.com 